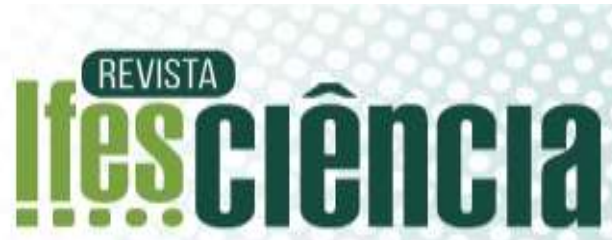

\section{COMPARAÇÃO DE SABERES ETNOHERPETOLÓGICOS ENTRE ALUNOS DE ESCOLA RURAL E URBANA}

\author{
COMPARISON OF ENTOHERPETOLOGICAL KNOWLEDGE BETWEEN \\ RURAL AND URBAN STUDENTS SCHOOL
}

\author{
${ }^{1}$ Thamyris Ribeiro Batista* \\ 2 Thaís de Assis Volpi \\ ${ }^{1}$ Instituto Federal do Espírito Santo, campus Santa Teresa. E-mail: thamyrisrbatista@gmail.com \\ ${ }^{2}$ Instituto Federal do Espírito Santo, campus Santa Teresa. E-mail: thaisvolpi@gmail.com \\ *Autor de correspondência
}

Artigo submetido em 27/04/2020, aceito em 08/09/2020 e publicado em 28/12/2020.

\begin{abstract}
Resumo: Etnoherpetologia visa compreender o conhecimento popular associado a anfíbios e répteis. A relação dos humanos com o meio é construída desde a infância, quando se inicia o processo de interação com o mundo. Este conhecimento intrínseco reforçado pelo senso comum é construído ao longo do tempo e pode perpetuar explicações simplistas ou errôneas de processos biológicos que não são compreendidos sem conhecimento científico. Com isso, o presente estudo investigou os saberes populares de alunos de uma escola rural e uma urbana acerca das serpentes. A pesquisa foi conduzida durante o segundo semestre de 2019 entre alunos do $6^{\circ}$ ano, pois ainda não estudaram zoologia no ambiente escolar. Foram investigados 52 alunos de escolas do estado do Espírito Santo, sendo 27 de uma escola rural de Santa Teresa e 25 de escola urbana de Cariacica. Constatou-se que todos os alunos compreendem que a principal prática de primeiros socorros em acidentes ofídicos é conduzir a vítima ao hospital. Porém, foram preocupantes as menções de métodos perigosos e caseiros. Foi verificado um grande percentual de alunos cujas experiências de encontro com as serpentes envolveram matança do animal, principalmente na zona rural, onde os encontros foram mais comuns. Apenas alunos que nunca tiveram contato com serpentes não cogitaram a matança como atitude primária a ser tomada. Atividades educativas são importantes iniciativas para minimizar as ameaças sofridas pelas serpentes, visto que ainda despertam sentimentos de medo e repulsa, tornando-as mais suscetíveis a injúrias antrópicas, mesmo quando não conferem qualquer ameaça.
\end{abstract}

Palavras-chave: Conhecimento Tradicional; Ameaças Antrópicas; Ofídios; Torniquete.

Abstract: Ethnoherpetology aims to understand the popular knowledge associated with amphibians and reptiles. The relationship of humans with the environment happens since childhood, when the process of interaction with the world begins. This intrinsic knowledge reinforced by common sense occur over time and can perpetuate simplistic or erroneous explications of biological processes that are not understood without scientific knowledge. With this, we investigated the popular knowledge of students from a rural and an urban school about snakes. We conducted the research during the second half of 2019 among students that not yet studied zoology. We investigated 52 students from schools in the state of Espirito Santo, being 27 from a rural school in Santa Teresa and 25 from an urban school in Cariacica. We found that all students understand that the main practice of first aid in snake accidents is to take the victim to the hospital. However, some students mention dangerous and homemade methods. We verify that large percentage of students whose experiences of encounters with snakes involved killing the animal, especially in rural areas, where encounters were more common. 
Only students who have never had contact with snakes not considered killing snakes as a primary action. Educational activities are important initiatives to minimize the threats suffered by snakes, since they still arouse feelings of fear and disgust, making them more susceptible to anthropic injuries, even when they do not confer any threat.

Keywords: Traditional Knowledge; Anthropical Threats; Ophidia; Tourniquet.

\section{INTRODUÇÃO}

As serpentes são representadas por 3.789 espécies viventes descritas (UETZ, 2015), sendo registradas 405 no Brasil e sendo 202 espécies na região Sudeste (COSTA e BÉRNILS, 2018). Destas, cerca de $15 \%$ apresenta importância médica, principalmente espécies das famílias Elapidae e Viperidae. Estes animais fornecem inúmeros princípios ativos para elaboração de medicamentos para hipertensão e analgésicos (PAZINATO, 2013; CHAGAS, 2015; NÓBREGA, 2019). Desempenham ainda grande importância em outros segmentos, tais como a prestação de serviços ecossistêmicos, tendo em vista que participam de inúmeras interações ecológicas (LIMA-VERDE, 1994), atuando inclusive no equilíbrio ecológico e controle de pragas (LEMA, 2002; CAMPOS, 2018).

Porém, são mais populares por sua periculosidade do que pela importância que desempenham, embora sejam poucas espécies a causar injúrias aos humanos. $\mathrm{O}$ conhecimento associado às serpentes está em sua maioria associados a fatores negativos, o que pode favorecer agravos acometidos a estes animais, causando assim a redução das espécies, peçonhentas ou não, visto que são consideradas em sua totalidade como animais perigosos. Assim, é possível que os conflitos entre humanos e serpentes sejam potencializados (CARDOSO et al., 2003), causando o extermínio das espécies, incluindo situações em que o animal não confere ameaça, tais como atropelamentos intencionais. Por isso, nem sempre o conhecimento popular, construído na infância e perpetuado ao longo das gerações, apresenta fundamentação científica (SILVA et al., 2016). Assim, o aumento do conhecimento científico das pessoas sobre as serpentes poderia minimizar o temor associado a estes animais, visto que, a maior parte das espécies não oferece qualquer risco aos seres humanos.

No entanto, parte deste temor é justificado pelos acidentes ofídicos que promoveram 269 mortes em 2017 no Brasil (DATASUS, 2017) e 5.508 acidentes (BRASIL, 2017). Estes acidentes estão relacionados predominantemente a atividades humanas em meio rural (SANDRIN et al., 2005), onde estes animais são mais comumente encontrados. Por isso, ações preventivas e educativas direcionadas a tais populações poderiam atenuar os registros de acidentes e mortes por causas ofídicas (BERNARDE et al., 2018).

Por isso, é de suma importância que seja investigado o conhecimento humano acerca da fauna com a qual está relacionado, de maneira a tornar mais eficientes campanhas de educação científica que, além de promover a conservação das serpentes, auxiliará na qualidade de vida da comunidade, visto que minimizaria as experiências danosas com estes animais (COSTA-NETO, 2000). Neste contexto, encontra-se a etnoherpetologia, que é a área de investigação que visa compreender o conhecimento popular e tradicional, tais como as lendas e crenças associadas a anfíbios e répteis (COSTA-NETO, 2000; BARBOSA et al., 2007).

Considerando a importância de conhecer como as populações humanas compreendem e interagem com as serpentes, o presente estudo teve como objetivo investigar os saberes populares 
alunos de uma escola rural e uma urbana acerca destes animais. Para isso, foram verificadas as seguintes hipóteses: (i) tanto alunos de escola rural quanto urbana detém igual conhecimento acerca das serpentes, tendo em vista que apresentam o mesmo grau de escolaridade, sendo irrisória a influência do contexto social; (ii) os alunos da escola rural sabem mais sobre as serpentes, devido ao contexto social ao qual estão inseridos, que os permite maior interação com os animais; e (iii) os alunos da escola urbana detém mais conhecimento científico sobre as serpentes, pois possuem mais acesso à internet e a informações com embasamento teórico.

\section{REFERENCIAL TEÓRICO}

A biodiversidade está diretamente ligada a qualidade de vida humana, visto que dependemos diretamente dos recursos naturais disponíveis, além do conhecimento de seus potenciais econômicos e medicinais. Apenas através do conhecimento da biodiversidade que se torna possível identificar todas as suas potencialidades (DIAZ et al., 2006). O conhecimento sobre a biodiversidade nunca se fez tão emergencial. Isso porque, anualmente muitas espécies são extintas por causas antrópicas mesmo antes de serem conhecidas pela ciência (MYERS $e t$ al., 2000).

O Brasil abriga uma das maiores biodiversidades do planeta, com grande representatividade de espécies endêmicas (BRASIL, 2017). No entanto, o conhecimento sobre esta diversidade ainda é muito incipiente, mesmo com diversas iniciativas bem-sucedidas para contornar tal problema. A falta de conhecimento sobre a diversidade biológica e seus potenciais pode ameaçá-la em algum nível, visto que acentua os impactos antropogênicos, como modificação de habitats e perda de patrimônio biológico (CATANOZI, 2011). Dentro desta biodiversidade, se encontram as serpentes, que formam um dos grupos de répteis mais diversificados no mundo, com mais de 3.789 espécies viventes descritas (UETZ, 2015). O Brasil apresenta 405 espécies descritas, sendo metade delas encontradas na região Sudeste (COSTA e BÉRNILS, 2018).

Dentre toda esta diversidade brasileira, $15 \%$ das espécies apresentam importância médica, principalmente representantes das famílias Elapidae e Viperidae. Diversas toxinas de diferentes tipos de animais vêm sendo isoladas e muitas delas são consideradas grandes ferramentas para pesquisa básica e alvos farmacológicos, que podem ser usadas no tratamento de dores, diabetes, esclerose múltipla, doenças cardiovasculares, dentre outras (LEWIS e GARCIA, 2003). As serpentes fornecem vários princípios ativos com grande potencial farmacológico, que são usados na elaboração medicamentos altamente eficientes para hipertensão e analgesia.

Os principais medicamentos utilizados para o tratamento da hipertensão foram elaborados a partir do veneno de jararaca da espécie Bothops jararaca (PAZINATO, 2013). Além deste, outro medicamente elaborado a partir do veneno de serpentes é o "Enpak" (sigla para endogenous pain killer), uma proteína com poder analgésico obtida do veneno da cascavel da espécie Crotalus terrificus, cujo efeito pode vir a ser mais poderoso do que o da morfina (CHAGAS, 2015). O veneno da surucucu (Lachesis muta) também apresenta potencial farmacológico. Até o ano 2000, não havia soro antiofídico contra o seu veneno, e a partir de sua descoberta, o Instituto Butantan vêm desenvolvendo estudos de uma fração imunossupressora desse veneno, que tem a capacidade de diminuir a resposta imunológica do organismo. Como esta substância não induz anticorpos e não é tóxica para o ser humano, futuramente poderá ser usada para transplantes - evitando a rejeição de órgãos, doenças autoimunes (artrite, lúpus e esclerose múltipla), além de evitarem 
reações alérgicas e infecções (NÓBREGA, 2019).

Além disso, desempenham importantes serviços ecossistêmicos, devido a interações tróficas que realizam com os outros animais (LIMA-VERDE, 1994), pois, atua como presa e como predador, muitas vezes promovendo o equilíbrio ecológico através do controle de pragas (LEMA, 2002; CAMPOS, 2018). No entanto, ainda são animais mais conhecidos pela periculosidade do que pela importância que desempenham.

Para compreender o conhecimento das pessoas sobre a biodiversidade zoológica, encontram-se áreas de estudo como etnozoologia, que busca entender a interação que uma comunidade mantém com a fauna de sua região, levando em consideração a cultura e os costumes populares (SANTOS-FITA et al., 2007). A relação entre pessoas e animais é construída desde a infância, quando se inicia $\mathrm{o}$ processo de interação com $\mathrm{o}$ mundo e com a cultura local, o que leva a uma interpretação própria acerca dos organismos circundantes. Este conhecimento intrínseco construído ao longo do tempo pode contribuir para a perpetuação de conceitos equivocados sobre a ecologia dos animais, fomentando no imaginário uma explicação simplista para o que não é compreensível sem um conhecimento técnico e científico, embasada apenas pelo senso comum (SILVA et al., 2016).

Uma das subáreas de investigação da etnozoologia é a etnoherpetologia, que visa a compreensão do conhecimento popular, tais como lendas e crenças envolvendo anfíbios e répteis (COSTANETO, 2000; BARBOSA et al., 2007). Animais como as serpentes, tradicionalmente temidos e pouco compreendidos, se inserem no imaginário popular a inúmeras crenças e mitos, muitas vezes negativos, que podem contribuir para o seu extermínio antrópico, favorecendo assim a redução das espécies.
As serpentes possuem uma relação com os seres humanos desde os tempos mais antigos, fazendo parte de diversas crendices populares por estar, na maioria das vezes, associado à representação do mal na Terra (CARDOSO et al., 2003). Uma destas representações é mencionada na Bíblia Sagrada, onde as serpentes representam o mal, conduzindo Adão e Eva ao pecado, sendo por isso expulsos do paraíso (LIMA et al., 2018).

Parte deste temor apresenta algum fundamento, vista a periculosidade de algumas espécies, muito embora representem a minoria. No ano de 2017, ocorreram 269 mortes no Brasil e foram provocadas por acidentes ofídicos, e no ES teve 10 registros no estado (DATASUS, 2017). As principais espécies envolvidas em acidentes com humanos são principalmente das famílias Viperidae e Elapidae. Quanto aos acidentes ofídicos registrados no Brasil, o número de notificações em 2008, foi de 26.156 casos, correspondendo à incidência de 13,8\% casos por 100.000 habitantes. No Sudeste, o número de casos em 2008 foi de 6.043 (BRASIL, 2009), tendo uma redução de $21 \%$ em relação as notificações em 2017 (BRASIL, 2017). Neste mesmo ano, foram notificados 10 casos no município de Santa Teresa, Espírito Santo.

A ocorrência desses acidentes está relacionada principalmente à atividade humana no campo, seja profissional ou lazer (SANDRIN et al., 2005). Considerando o fato de as vítimas de acidentes ofídicos serem pessoas predominantemente de área rural, é estratégico e fundamental ações educativas, preventivas e de primeiros socorros que tenham como público-alvo estas pessoas, além de estudantes e outros segmentos da sociedade, que podem atuar como agentes multiplicadores, levando o aprendizado até suas famílias (BERNARDE et al., 2018).

Embora apenas poucas espécies de serpentes possam causar algum dano a saúde humana, o estereótipo negativo 
costuma estar associado a todas as espécies, peçonhentas ou não, que são consideradas em sua totalidade como animais perigosos. Esta percepção popular pode potencializar conflitos entre humanos e serpentes (CARDOSO et al., 2003), podendo haver um extermínio das espécies, incluindo situações em que o animal não confere ameaça, tais como atropelamentos intencionais. O temor e os atos de matanças envolvendo as serpentes podem ocorrer devido à falta de informação (FREITAS, 2003).

$\mathrm{O}$ enorme desconhecimento acerca destes animais gera uma relação conflituosa entre humanos e serpentes. Por isso, se faz necessário difundir o conhecimento científico acerca destes animais de forma a demonstrar sua importância ao meio ambiente e ao ser humano, buscando minimizar tais conflitos. $\mathrm{O}$ aumento sobre $\mathrm{O}$ conhecimento das pessoas sobre as serpentes pode minimizar o temor associado a tais animais, tendo em vista a maior parte das espécies não oferece qualquer risco aos seres humanos.

Investigar o conhecimento de uma determinada comunidade humana sobre a fauna local é fundamental para definir e orientar campanhas educativas que visem a subsequente conservação das espécies, além de auxiliar na qualidade de vida da comunidade, minimizam as experiências humanas danosas, tais como acidentes ofídicos. Com isso, estudos que visem mitigar os acidentes ofídicos através da educação ambiental, principalmente em regiões de maior incidência, tais como em populações agrícolas e cafeeiras, são de suma importância, já que as ações beneficiam tanto as comunidades humanas quanto as serpentes (COSTA-NETO, 2000).

\section{MATERIAIS E MÉTODOS Local de estudo}

A investigação foi conduzida com os alunos do $6^{\circ}$ ano do Ensino Fundamental de duas escolas do estado do
Espírito Santo: uma da zona rural e uma urbana. Os alunos da zona rural investigados são procedentes da Escola Municipal de Educação Infantil e Ensino Fundamental "Paulino Rocon", localizada no distrito de Alto Caldeirão, município de Santa Teresa. Já os alunos de zona urbana procedem da Escola Municipal de Ensino Fundamental "Talma Sarmento de Miranda", localizada no município de Cariacica, Espírito Santo.

\section{Amostra}

A investigação foi conduzida com 52 alunos do $6^{\circ}$ ano de escolas públicas municipais da zona rural (27) e urbana (25) com idade entre 11 e 15 anos, sendo 19 do sexo feminino e 33 do sexo masculino. A escolha de alunos desta escolaridade se deu pelo fato do conteúdo de zoologia incluindo serpentes, ainda não ter sido trabalhado em sala de aula. Além disso, a escolha de alunos de diferentes procedências (zona rural e urbana) permitiram a obtenção de informações de diferentes contextos sociais, que podem exercer influência no conhecimento que os alunos apresentam sobre as serpentes. Isso porque alunos de escola rural podem apresentar maior aproximação com a natureza e mais contato com as serpentes, e com isso mais conhecimento empírico, embora não necessariamente com embasamento científico. Considerando que o acesso à informação pode ser facilitado em centros urbanos, é possível que alunos provenientes destes locais detenham mais informações científicas acerca das serpentes. Tais comparações só são possíveis graças à investigação de grupos amostrais de procedências distintas, como o conduzido no presente estudo.

\section{Coleta e análise de dados}

O estudo foi conduzido ao longo do segundo semestre do ano de 2019. Ao primeiro contato, foi esclarecido aos entrevistados o objetivo da pesquisa, a fim de verificar a possibilidade de participação. Aos interessados, foi entregue um Termo 
de Consentimento Livre e Esclarecido, além de um Termo de Assentimento, referentes a obtenção de consentimento dos responsáveis e do assentimento do aluno na investigação, respectivamente, de acordo com as instruções normativas do Comitê de Ética do Instituto Federal do Espírito Santo, campus Santa Teresa. A partir do consentimento e assentimento fornecido pelos alunos e seus respectivos responsáveis, foram aplicados questionários do tipo qualitativo e quantitativo composto por questões abertas e fechadas semiestruturadas, utilizando os pressupostos teórico-metodológicos da pesquisa participante.

A pesquisa participante parte da realidade da comunidade entrevistada, em que o pesquisador não deve deixar de lado as interações que a comunidade apresenta com outros segmentos que compõem a vida destes indivíduos, fazendo o exercício de se colocar como sujeito da comunidade a fim de compreender a realidade social, visto que todas as culturas são fontes de saber (BRANDÃO e BORGES, 2008). A pesquisa participante busca distinguir a ciência popular da dominante, colocandose a serviço dos menos favorecidos e o posicionamento destes em sua comunidade. Neste tipo de pesquisa, a ciência popular é entendida como o conhecimento derivado do senso comum, visto que este permitiu a criação e interpretação da realidade a partir dos recursos oferecidos pela natureza. Já a ciência dominante é vista como uma atividade que visa a manutenção do sistema vigente (GIL, 2002).

Os dados analisados de forma quantitativa referiram-se a perguntas fechadas ou de caráter qualitativo, quando as respostas dos entrevistados foram convergentes. Já os dados analisados de maneira qualitativa referiram-se a posicionamentos idiossincráticos em que não é possível analisar por dados numéricos. Desta forma, as questões abertas, dependendo da resposta dos entrevistados, foram avaliadas tanto qualitativa quanto quantitativamente. Já as questões fechadas foram analisadas apenas de maneira quantitativa.

\section{RESULTADOS E DISCUSSÃO Conhecimento sobre as serpentes}

Ao serem questionados sobre o conhecimento que detêm acerca das serpentes, $81,5 \%$ os alunos de zona rural disseram que existem cobras venenosas e outras não venenosas, que um acidente com elas poderia levar a morte, ao qual atribuem a fonte de informação a internet e familiares. Além destes, 14,8\% disseram que o veneno da cobra é usado como soro antiofídico nos casos de acidentes, enquanto apenas $3,7 \%$ disseram que não sabem nada sobre as cobras. Já entre os alunos de zona urbana, $60 \%$ disseram não saber nada, um percentual muito expressivo. Aos alunos que relataram saber algo sobre as serpentes, estes atribuíram as informações obtidas a documentários, internet e familiares. Além disso, tiveram relatos de informações muito específicas, como o relato de metade destes alunos sobre o fato de as serpentes não possuírem ouvido e usarem a língua para sentir as ondas sonoras, enquanto os demais atribuíram a letalidade apenas a algumas espécies.

Com isso, é possível identificar uma grande desproporcionalidade no que fiz respeito aos relatos de não saberem nada sobre serpentes, que correspondeu a maioria dos alunos da zona urbana e a uma parcela ínfima dos alunos de zona rural, que relataram muito conhecimento empírico sobre elas. No entanto, entre os alunos de zona urbana que sabiam algo sobre serpentes, houve relatos muito específicos com embasamento científico. Com isso, é possível que as informações com maior riqueza de detalhes fornecidas pelos alunos tenham sido obtidas por meios como internet, documentários, televisão, e demais veículos de maior acesso ao dia a dia do aluno, visto que as escolas não são os únicos locais onde as 
pessoas podem aprender sobre a natureza da ciência (SILVA, 2006).

Portanto, a hipótese do presente estudo de que os alunos, independente do contexto em que estão inseridos (rural e urbano), detém o mesmo conhecimento acerca das serpentes, já que apresentam o mesmo grau de escolaridade, não é corroborada, haja vista a distinção nas respostas fornecidas entre os dois grupos. No entanto, a hipótese de que os alunos da escola rural sabem mais sobre as serpentes, devido ao contexto social ao qual estão inseridos que os permite maior interação com os animais, pode ser corroborada, desde que consideremos o conhecimento empírico e tradicional, não presente entre os alunos de zona urbana.

Em relação ao que se deve fazer no caso de um acidente com serpente peçonhenta, $81,5 \%$ dos alunos de zona rural disseram que é preciso levar a pessoa acidentada ao hospital mais próximo. Dentro deste grupo, tiveram relatos interessantes, como de que é preciso levar a cobra junto $(3,7 \%)$, que o uso de remédios caseiros seria eficiente até a chegada ao hospital $(3,7 \%)$ e que colocar folha de taioba no local da picada ajuda a evitar que o veneno espalhe $(3,7 \%)$. No entanto, houve um relato preocupante, como o de $18,5 \%$ que disseram que amarrariam uma corda ou fariam um torniquete até chegar ao hospital. Já entre os alunos de zona urbana, observou-se que um percentual menor de alunos relatou que é necessário levar a pessoa acidentada ao hospital (64\%), enquanto uma parcela significativa disse que não saberia o que fazer nesta situação (24\%) ou mesmo os que amarrariam uma corda ou barbante no local da picada até chegar ao hospital $(12 \%)$.

Em vista disso, é possível identificar que, mesmo a maioria dos entrevistados tendo noção de que o melhor a se fazer é levar a pessoa acidentada ao hospital, muitos mencionam métodos errôneos e perigosos de tratamento que não são eficazes nem recomendados pelo
Ministério da Saúde, tais como torniquetes, garrotes e remédios populares, pois pode agravar o quadro da vítima (BRASIL, 2001; LIMA et al., 2018). No entanto, apenas entre os alunos de zona rural foram mencionadas práticas como levar a serpente ao hospital ou utilizar-se de taioba para conter o veneno, saberes que podem estar associados a tradições locais. Ribeiro e Jorge (1997) apontam que a utilização do torniquete também foi uma prática verificada em 38,2\% nos pacientes do Hospital Vital Brazil do Instituto Butantan entre 1981 e 1990, ressaltando que até pouco tempo esta era uma prática ainda muito recorrente, embora careçam de dados atualizados deste cenário. Vizotto (2003) relata que estas formas de tratamento são bastante comuns no Brasil. Procedimentos como o uso do torniquete ainda são citados como eficazes em livros didáticos escolares (SANDRIN et al., 2005).

\section{Experiência dos alunos com as serpentes}

Em relação a experiência e contato dos alunos com as serpentes, todos de zona rural relataram que já haviam tido algum encontro com estes animais. Quando perguntados sobre a atitude tomada diante do encontro, 70,3\% disseram que chamaram alguém para matar o animal e $29,7 \%$ disseram que o deixaram ir embora. Já entre os alunos de zona urbana, apenas $40 \%$ responderam que já haviam encontrado alguma serpente. A estes, foi perguntado que atitude foi tomada, ao qual $60 \%$ disseram que saíram correndo e $40 \%$ disseram que a serpente foi morta. Já entre os alunos que nunca haviam encontrado alguma cobra, $73,3 \%$ disseram que correriam, $20 \%$ não saberiam o que fazer, e $6,7 \%$ matariam o animal.

Tais resultados são congruentes com as hipóteses previamente elaboradas, visto que o avistamento de serpentes foi muito mais representativo entre os relatos de alunos da zona rural, onde espera-se que estes animais sejam mais comumente encontrados. Foi possível notar ainda um 
percentual muito expressivo de alunos tanto de zona rural quanto urbana - cuja experiência de interação com as serpentes acarretou a matança do animal como atitude mais provável ou possível de ser tomada. Pelo fato dos alunos do presente estudo ainda não terem estudado o conteúdo de zoologia na escola, podem não compreender com clareza o que são as serpentes, a sua importância e o quão negativamente afetaria estas espécies atitudes errôneas ou precipitadas, como a matança indiscriminada, mesmo quando o animal não confere ameaça. Por isso, os sentimentos gerados por estes animais foram preponderantes nas atitudes registradas nos encontros com estes animais.

Moura et al. (2010) em seus estudos, verificou que $46 \%$ dos entrevistados que tiveram contato com as serpentes optaram por matá-las, vista a associação que fazem entre elas e um risco iminente. Atitudes extremas de matança animal podem ser atribuídas a diversos fatores, tais como a associação de ameaça ao bem-estar humano relacionado a todas as serpentes, a falta de conhecimento sobre suas reais ameaças, além do fato de não serem aprazíveis aos olhos, o que gera uma sensação de nojo, repulsa e medo (STAHNKE et al., 2009). Vizotto (2003), relata que a relação estabelecida com as serpentes é conflituosa, e por isso, na maioria das vezes, desencadeia a morte ou repúdio por esses animais.

No entanto, a atitude de matar o animal foi mais comumente verificada entre os alunos que já tiveram algum contato com as serpentes. Isso porque um percentual muito pequeno de alunos que nunca tiveram contato com o animal tomaria a atitude de matá-lo, caso o encontrasse. A maior parte destes alunos (zona urbana) tomaria a atitude de se afastar ou mesmo não saberiam o que fazer diante do encontro, mas não tiveram necessariamente o ímpeto da matança. Isso pode evidenciar que as crianças não tendem racionalmente e a priori tomar uma atitude extrema como a matança, mas que na prática a atitude, executada pelo adulto, pode influenciar na perpetuação desta ideia em seu imaginário.

Ao serem questionados se conheciam alguém que já havia sido picado por serpentes e que atitudes foram tomadas nestas situações, $44,4 \%$ dos alunos da zona rural disseram que alguém da família já havia sofrido um acidente ofídico. Destes acidentes, $66,7 \%$ mencionaram que a pessoa foi levada ao hospital, e 33,3\% que além de levar a pessoa ao hospital, a serpente também foi morta. Aos demais que não conheciam ninguém que já tenha sofrido um acidente ofídico, todos responderam que a atitude que tomariam seria conduzir a pessoa ao hospital. Nenhum dos alunos da zona urbana relatou conhecer alguém que já tenha sofrido algum acidente com serpentes. No entanto, caso tal acidente ocorresse, mais da metade $(52 \%)$ relatou que não saberia o que fazer, $24 \%$ disseram que chamariam alguém e $24 \%$ conduziria o acometido ao hospital.

Neste caso, é possível observar que, embora o acesso a informação seja maior na atualidade, ainda é alto o número de pessoas da zona urbana que não saberia o que fazer em uma situação de acidente ofídico. $\mathrm{O}$ desconhecimento sobre tais práticas pode estar associado ao fato de que o contato com as serpentes por estes alunos não corresponde a realidade de seu contexto social e, portanto, pode não ser uma preocupação que gere reflexão prévia destes alunos, tampouco de seus responsáveis em promover a disseminação de informações sobre este tema. Balestrin et al. (2002) afirma que a ausência do animal na região da zona urbana ou longe do cotidiano dos alunos, caracteriza também num distanciamento de informações sobre as serpentes, o que abre espaço para uma interpretação errônea ou superficial acerca destes animais. Isso poderia explicar o alto número de alunos da zona urbana verificados no presente estudo que não saberia o que fazer ao 
encontrar uma serpente ou em caso de acidente ofídico.

É importante ressaltar ainda o alto número de alunos que compreendem como práticas de primeiros socorros atitudes prudentes, seguras e recomendadas, como a condução da vítima ao hospital, o que pode minimizar os impactos gerados por estes acidentes, caso ocorram.

\section{Conhecimento sobre a ecologia de serpentes}

Foi verificado o conhecimento intrínseco que os alunos detinham sobre os locais onde as serpentes são mais comumente encontradas. Entre os alunos de zona rural, 96,2\% disseram que são encontradas em matas, enquanto os demais as associaram a lugares secos, como plantações de café e eucalipto. Embora todos os alunos da zona rural já tenham citado conhecer pessoas que sofreram acidentes ofídicos, além da maior parte destes acidentes ocorrerem entre agricultores (SARAIVA et al., 2012), é contraintuitivo supor que poucos deles associem a presença das serpentes a plantações.

A maior parte dos alunos de zona urbana $(88 \%)$ também associou estes animais as matas, enquanto uma pequena parcela não soube dizer onde são encontradas (4\%), ou mesmo as associaram às cidades (4\%) ou todos os lugares de maneira genérica (4\%). Embora não seja comum, as populações da zona urbana também podem ser acometidas por acidentes ofídicos, o que explica o relato de alunos associarem as serpentes também às cidades, além das florestas. Embora o habitat natural das serpentes seja em florestas, a urbanização vem fazendo com que haja a redução de área florestal para o crescimento urbano, forçando 0 deslocamento de serpentes para outros ambientes (CAMPOS, 2018), como centros urbanos. Vale salientar que, mesmo não tendo estudado estes animais no ambiente escolar, a maior parte dos alunos da zona urbana apresentam respostas assertivas ao entender e relacionar as matas como o principal local de aparição das serpentes.

\section{Serpentes: venenosas ou peçonhentas?}

A diferença entre animais venenosos e peçonhentos nunca foi completamente compreendida pelo público leigo, e não costuma ser claro quando se vislumbra estes termos sob a ótica do conhecimento instrínseco e popular. Por isso, ao serem perguntados se as serpentes são venenosas ou peçonhentas, 48,2\% dos alunos da zona rural as definiram como venenosas e peçonhentas, $37 \%$ não saberiam determinar a diferença destes termos, enquanto $14,8 \%$ disseram que eram venenosas, sendo que não houve nenhum relato de serem apenas peçonhentas. Já entre os alunos da zona urbana, 68\% disseram que as cobras são venenosas e peçonhentas, $28 \%$ disseram que eram apenas venenosas e $4 \%$ não saberiam dizer a diferença destes termos, não havendo nenhum relato de que fossem apenas peçonhentas.

As serpentes podem ser classificadas em dois principais grupos: as peçonhentas, que são as que conseguem inocular o veneno na presa, e as não peçonhentas, que produzem um veneno que aflora em sua cavidade bucal, mas não possuem presas inoculadoras para introduzir o veneno na vítima (BRASIL, 2001). Assim, a definição cientificamente congruente é de que as serpentes perigosas sejam associadas a animais peçonhentos, visto que tal definição já engloba o fato de serem venenosas, com o adicional de terem aparatos morfológicos de inoculação do veneno.

Não é de se surpreender a não associação dos alunos de serpentes e peçonha, tendo em vista que ainda não tiveram contato em ambiente escolar com termos técnicos e muito específicos de zoologia. Portanto, as diferenças entre estas definições não são claras para os alunos. Isso porque uma parte representativa de alunos definiu as 
serpentes como venenosas e peçonhentas ou apenas venenosas, não havendo nenhuma associação específica de que fossem apenas peçonhentas. Estes dados demonstram ainda que, apesar dos alunos da zona rural viverem em ambientes propícios a aparições das serpentes e terem mais contato com estes animais, é alto o número dos que não sabem a diferença desses termos, evidenciando que o conhecimento empírico não inclui a distinção entre animais venenosos ou peçonhentos.

Souza e Souza (2005) afirmam que, o desconhecimento ou a interpretação equivocada acerca da história de vida de alguns animais, principalmente os peçonhentos e venenosos, somado aos mitos e lendas associados a eles, devem ser confrontados com os conhecimentos prévios dos alunos, a fim de conscientizálos sobre a importância da preservação das espécies, ou pelo menos evitar o conflito entre humano-animal. Além disso, a distinção destes termos permite que seja explicado que são poucas as espécies peçonhentas e capazes de inocular veneno na corrente sanguínea e, portanto, a maioria não causa ameaças aos seres humanos.

\section{Uso da internet para aprendizado de ciências}

Foi verificado quanto tempo por dia os alunos usam a internet para obter informações sobre ciências. Entre os alunos da zona rural, $66,6 \%$ disseram que usam de duas a quatro horas por dia a internet como fonte referencial e 33,3\% responderam que não usam a internet para o aprendizado de ciências. Já entre os alunos da zona urbana, $44 \%$ responderam que usam a internet de duas a quatro horas por dia para aprender ciências, $44 \%$ responderam que não usam a internet para estes fins, enquanto $12 \%$ disseram que usam, mas em tempo bem reduzido e com a finalidade de assistir vídeos e jogos de serpentes.
Assim, a hipótese de que os alunos da escola urbana possuem mais acesso à internet e a informações científicas deverá ser parcialmente refutada. Embora não seja possível saber se há diferença na acessibilidade entre a zona rural e urbana, é possível notar que os alunos da zona rural utilizam a internet por mais tempo para fins educativos e, portanto, poderiam estar mais bem informados cientificamente que os alunos de zona urbana, considerando que consomem mais informações com embasamento na internet.

Segundo pesquisas do Núcleo da Informação e Coordenação do Ponto Brasil e Centro Regional de Estudos para o Desenvolvimento da Sociedade da Informação, indivíduos entre 11 e 17 anos utilizam a internet de quatro horas ou mais por dia em média, mas a maioria não o faz para fins educativos, e sim para atividades relacionadas a comunicação e interação social na rede (NIC-CETIC, 2018). Por isso, o uso de internet para fins educativos, principalmente entre os alunos de zona rural é de importante relato, visto que através disso foi possível identificar o grande potencial desta ferramenta para a educação ambiental e difusão científica, mesmo em regiões rurais. Embora uma expressiva quantidade de alunos consuma a internet para fins de aprendizado, é alto o percentual de alunos que não a utilizam com este objetivo. O aumento do uso de tais ferramentas para fins educativos poderia minimizar o desconhecimento que muitos apresentam sobre as serpentes.

\section{$O$ ensino de ciências e o meio ambiente}

As alterações ambientais despertaram no ser humano uma preocupação com o futuro do planeta. Portanto, encontrou-se na educação uma ferramenta essencial na luta pela preservação do meio ambiente. Como uma aliada no processo de conservação, surgiu a educação ambiental, aplicada nos segmentos formais e informais da educação (MUZOLON et al., 2019). Esta prática visa o despertar da consciência 
ambiental na sociedade, pois através dela cada pessoa pode modificar seus hábitos e adquirir novos valores na redução da degradação ambiental, melhorando a qualidade de vida. Pode ser um instrumento valioso para formar uma população consciente e preocupada com os problemas ambientais, tendo conhecimento e consequentemente podendo promover ações participativas para a preservação do meio ambiente.

Através da educação não formal, as atividades propostas fora da sala de aula tornam-se mais atrativas, estimulam a curiosidade e facilitam a construção do conhecimento do aluno. As escolas possuem um papel fundamental de transmitir informações e conhecimento científico sobre o meio ambiente, objetivando $\mathrm{o}$ pensamento crítico e consciente, propondo ideias e soluções que auxiliarão no desenvolvimento sustentável e na mitigação dos danos causados ao meio ambiente (MELLO, 2017). Após o contato do aluno com o conhecimento sobre o meio ambiente ecologicamente equilibrado, há o entendimento de seu papel neste contexto, compreendendo assim a importância da conservação ambiental para o bem-estar humano e manutenção da espécie, e qual seu papel neste contexto a partir de uma visão não antropocêntrica, visto que compreenderiam que fazem parte do meio ambiente (AZEVEDO et al., 2012).

\section{CONCLUSÕES}

Os dados obtidos revelam que independente da sua localização, os alunos da zona rural quanto da zona urbana, possuem algum tipo de conhecimento relacionado às serpentes, principalmente no que tange as práticas de primeiros socorros em acidentes ofídicos. No entanto, a menção de métodos perigosos e caseiros ainda é preocupante, tendo em vista os relatos chamam atenção, principalmente o alto número de alunos que relataram que suas experiências de encontro com as serpentes envolveram a matança do animal, principalmente na zona rural, onde os encontros foram mais comuns.

Em contrapartida, apenas os alunos de zona urbana, que nunca tiveram contato com as serpentes, não apresentaram $\mathrm{o}$ ímpeto de matar o animal como atitude primária, e por isso, atitudes extremas são verificadas como relato de experiência, mas não são atitudes que necessariamente seriam tomadas pelos alunos a priori. Assim, o estudo de ciências e atividades como educação ambiental se mostram importantes instrumentos para minimizar as ameaças sofridas pelas serpentes. Isso porque estes animais ainda são vistos de maneira negativa pela sociedade, despertando sentimento de nojo e medo, o que permite que sofram injúrias, mesmo quando não conferem qualquer ameaça.

\section{REFERÊNCIAS}

AZEVEDO, H.J.C.C.; FIGUEIRÓ R.; ALVES D.R.; VIEIRA, V.; SENNA A.R. $\mathrm{O}$ uso de coleções zoológicas como ferramenta didática no ensino superior: um relato de caso. Revista Práxis, n.7, p.4348. 2012.

BALESTRIN, R. L.; LEITAO-DEARAUJO, M; ALVES, M. L. M. Ocorrência de híbridos não naturais entre Bothrops jararaca e $B$. neuwiedi (Serpentes, Viperidae). Iheringia Série Zoologia, v. 92, n. 1, p. 85-90, 2002.

BARBOSA, A. R.; NISHIDA, A. K.; COSTA, E. S.; CAZÉ, A. L. R. Abordagem etnoherpetológica de São José da Mata, Paraíba, Brasil. Rev. Biol. Ciênc. Terra, v.7, n.2, p.17-123. 2007.

BERNARDE, P. S.; COSTA, J. G.; DUTRA, J. S.; SILVA, M. S.; SILVA, F. V. A. Ações educativas sobre primeiros socorros e prevenção de acidentes ofídicos no Alto Juruá (AC). South American Journal of Basic Education, Technical 
and Technological, v.5, n.2, p.289-299. 2018.

BRANDÃO, C. R.; BORGES, M. C. A pesquisa participante: um momento da educação popular. Revista de Educação Popular, v.6, p.51-62. 2007.

BRASIL, Ministério da Saúde. Manual de Diagnóstico e Tratamento de Acidentes por Animais Peçonhentos. Fundação Nacional de Saúde (FUNASA). 2 ed. Brasília, 120 p. 2001. Disponível em: <https://www.icict.fiocruz.br/sites/www.ici ct.fiocruz.br/files/Manual-de-Diagnosticoe-Tratamento-de-Acidentes-por-AnimaisPe--onhentos.pdf $>$. Acesso em: 20 abr. 2020.

BRASIL, Ministério da Saúde. Guia de vigilância epidemiológica. Secretaria de Vigilância em Saúde. Departamento de Vigilância Epidemiológica. 7 ed. Brasília, 816p. 2009. Disponível em: <https://bvsms.saude.gov.br/bvs/publicaco es/guia_vigilancia_epidemiologica_7ed.pd f>. Acesso em: 20 abr. 2020.

BRASIL, Ministério do Meio Ambiente. Biodiversidade Brasileira. Brasília. 2017. Disponível em: $<$ http://www.mma.gov.br/biodiversidade/b iodiversidade-brasileira>. Acesso em: 28 mai. 2019.

CAMPOS, G. L. S. Serpentes em áreas sinantrópicas no brejo de altitude paraibano: um inventário para educação. 2018. 30f. Monografia (Graduação em Ciências Biológicas) - Universidade Federal da Paraíba, Paraíba. 2018.

CARDOSO, J. L. C.; FRANÇA, F.O.S.; WEN, F.H.; MÁLAQUE, C.M.S.; HADDAD-JUNIOR, V. Animais peçonhentos no Brasil: biologia, clínica e terapêutica dos acidentes. Instituto de Medicina Tropical de São Paulo, v.46, n.6, p.338. 2003.
CATANOZI, G. Importância dos aspectos ecológicos na análise qualiquantitativa da macrofauna edáfica. Revista Ibirapuera, n.1, p.42-52. 2011.

CHAGAS, B. B. Purificação e caracterização de proteases do veneno da Pseudechis australis e de seus inibidores endógenos. 2015. 51f. Dissertação (Mestrado) - Curso de Ciências na Área de Tecnologia Nuclear, Autarquia Associada à Universidade de São Paulo, São Paulo, 2015.

COSTA-NETO, E. M. Conhecimento e usos tradicionais de recursos faunísticos por uma comunidade afro-brasileira: resultados preliminares. Interciencia, v.25, n.9, p.423-431. 2000.

COSTA, H. C.; BÉRNILS, R. S. Répteis do Brasil e suas Unidades Federativas: Lista de espécies. Herpetologia Brasileira, v.8, n.1, p.11-57. 2018.

DATASUS: Departamento de Informática do Sistema Único de Saúde, Ministério da Saúde. Acidente por animais peçonhentos - notificações registradas no sistema de informação de agravos de notificações. Disponível em: http://tabnet.datasus.gov.br/cgi/tabcgi.exe? sinannet/cnv/animaisbr.def. Acesso em: 19 mai. 2019.

DIAZ S.; FARGIONE, J.; CHAPIN III, F. S.; TILMAN, D. Biodiversity loss threatens human well-being. PloSBiology, v.4, n.8, e277, p.1300-1305.

FREITAS, M. A. Serpentes Brasileiras. Lauro de Freitas. 1 ed. São Paulo: Editora Lauro de Freitas, v.1, 160p. 2003.

GIL, A. C. Como elaborar projetos de pesquisa. 4 ed. ISBN 85-224-3169-8. São Paulo: Atlas, 2002.

LEMA, T. Os Répteis do Rio Grande do Sul: atuais e fósseis, biogeografia, 
ofidismo. Porto Alegre: EDIPUCRS, 264p. 2002.

LEWIS, R. J; GARCIA, M. L. Therapeutic potential of venom peptides. Nature Reviews Drug Discovery, Springer Nature, v.2, n.10, p.790-802. 2003.

LIMA, B. S; SOUZA, M. M; SOUTO, N. L; BARROS, A. B. Investigando o conhecimento etnoherpetológico dos cafeicultores sobre as serpentes do município de Inconfidentes, Minas Gerais. Ethnoscientia, v.3, p.1-13. 2018.

LIMA-VERDE, J. S. Por que não matar as nossas cobras? In: NASCIMENTO, L. B; BERNARDES, A. T; COTTA, G. A. (Eds). Herpetologia no Brasil I. Editora Biodiversitas, Belo Horizonte, p.92-101. 1994.

MELLO, L. G. A importância da educação ambiental no ambiente escolar. Ecodebate, v.1, n.1, p.1-4. 2017.

MOURA, M. R.; COSTA, H. C.; SÃOPEDRO, V. A.; FERNANDES, V. D; FEIO, R. N. O relacionamento entre pessoas e serpentes no leste de Minas Gerais, sudeste do Brasil. Biota Neotropica, FapUNIFESP (SciELO), v.10, n.4, p.133-141. 2010.

MUZOLON, G. B; DIAS, G. P; FURUTA, C. R. A. P. Educação ambiental: uma proposta de intervenção pedagógica na Reserva Ecológica Amadeu Botelho no município de Jaú. Revista Eletrônica da Educação, v.2, n.2, p.129-147. 2019.

MYERS, N.; MITTERMEIER, R.A.; MITTERMEIER, C.G.; FONSECA, G.A. B.; KENT, J. Biodiversity hotspots for conservation priorities. Nature, v.403, p.853-858. 2000.

NIC-CETIC. Núcleo da Informação e Coordenação do Ponto Brasil, Centro Regional de Estudos para o Desenvolvimento da Sociedade da
Informação. Pesquisa sobre o uso da Internet por crianças e adolescentes no Brasil: TIC Kids Online Brasil, 2018. Disponível em: http://cetic.br/arquivos/ kidsonline/2018/criancas. Acesso em: 26 out. 2019.

NÓBREGA, L. G. C. Recurso terapêutico homeopático no tratamento da cefaleia tensional. 2019. 40f. Monografia (Curso de Especialista em Homeopatia), Centro Alpha de Ensino, São Paulo, 2019.

PAZINATO, D. M. M. Estudo etnoherpetológico: Conhecimentos populares sobre anfíbios e répteis no município de Caçapava do Sul, Rio Grande do Sul. 2013. 65f. Monografia (Especialização) - Curso de Educação Ambiental, Universidade Federal de Santa Maria, Santa Maria, Brasil, 2013.

RIBEIRO, L. A; JORGE, M. T. Acidente por serpentes do gênero Bothrops: série de 3.139 casos. Revista da Sociedade Brasileira de Medicina Tropical, FapUNIFESP (SciELO), v.30, n.6, p.475480. 1997.

SANDRIN, M. F. N.; PUORTO, G; NARDI, R. Serpentes e acidentes ofídicos: um estudo sobre erros conceituais em livros didáticos. Investigações em Ensino de Ciências, v.10, n.3, p.281-298. 2005.

SANTOS-FITA, D; COSTA-NETO, E. M. As interações entre os seres humanos e os animais: a contribuição da etnozoologia. Revista Biotemas, n.20, v.4, p.99-110. 2007.

SARAIVA, M. G.; OLIVEIRA, D. S.; FERNANDES-FILHO, G. M. C.; COUTINHO, L. A. S. A.; GUERREIRO, J. V. Perfil epidemiológico dos acidentes ofídicos no Estado da Paraíba, Brasil, 2005 a 2010. Epidemiol. Serv. Saúde, v.21, n.3, p.449-456. 2012.

SILVA, M. V. Serpentes do Estado do Acre: Riqueza, dieta, etno- 
conhecimentos e acidentes ofídicos. 2006. 81f. Dissertação (Mestrado em Ecologia e Manejo de Recursos Naturais) Universidade Federal do Acre, Rio Branco. 2006.

SILVA, A. W. P.; CASTRO, S. M. V.; SILVA, M. D. B.; CASTRO, P. H. G.;

COSTA, J. B. Concepções sobre serpentes entre jovens estudantes do ensino médio: um diálogo entre ciência e cultura. Scientia Plena, v.12, n.6, p.1-13, 27. 2016.

SOUZA, C. E. P.; SOUZA, J. G. (Re)Conhecendo os animais peçonhentos: Diferentes abordagens para a compreensão da dimensão histórica, socioambiental e cultural das ciências da natureza. In: V Encontro Nacional de Pesquisa em educação em ciências. Anais... Bauru: Associação Brasileira de Pesquisa em Educação em Ciências, Atas do V ENPEC, n.5, p.1-9, ISSN 1809-5100. 2005.

STAHNKE, L F; DEMENIGHI, J. S.; SAUL, P. F. A. Educação relacionada aos anfíbios e répteis: a percepção e sensibilização no município de São Leopoldo (RS). Olam - Ciência \& Tecnologia, v.9, n.2, p.1-33. 2009.

UETZ, P. How many species? Reptile database. 2015. Disponível em: $<$ http://www.reptile-database.org/dbinfo/SpeciesStat.html>. Acesso em: 18 de mar. 2019.

VIZOTTO, L.D. Serpentes: lendas, mitos, superstições e crendices. Editora Plêiade, 240p. 2003. 